\title{
A large nationwide population-based case-control study of the association between intussusception and later celiac disease
}

\author{
Jonas F Ludvigsson ${ }^{1,2,3^{*}}$, Agneta Nordenskjöld ${ }^{4}$, Joseph A Murray ${ }^{3}$ and Ola Olén ${ }^{1,5}$
}

\begin{abstract}
Background: Case reports and case series studies suggest a positive association between intussusception and celiac disease (CD).

Methods: We contacted Sweden's 28 pathology departments and obtained data on 29,096 patients with biopsy-verified CD (equal to Marsh stage 3) through biopsy reports. Patients with CD were matched for age, sex, calendar period and county of residence with up to five reference individuals from the general population $(n=144,522)$. Cases of intussusception were identified from nationwide inpatient, hospital-based outpatient and day-surgery data from the Swedish Patient Register.

Odds ratios (ORs) for future CD in patients with intussusception were estimated using conditional logistic regression.

Results: 34 (0.12\%) individuals with CD had a diagnosis of intussusception vs. $143(0.10 \%)$ reference individuals, suggesting that intussusception was not a risk factor for later $C D(O R=1.17$; $95 \%$ confidence interval $(C l)=0.82-$ 1.67). The $\mathrm{OR}$ for $C D$ in patients with at least two records of intussusception was 0.40 ( $95 \% \mathrm{Cl}=0.06-2.99)$. In contrast, a post-hoc analysis showed that CD was associated with a statistically significantly increased risk of intussusception after $C D$ diagnosis (hazard ratio $=1.95 ; 95 \% \mathrm{Cl}=1.01-3.77$ ); however, this analysis was based on only 12 cases with both CD and intussusception.
\end{abstract}

Conclusion: We found no association between intussusception and future CD; and a mostly modest increased risk of intussusception after a diagnosis of CD.

Keywords: Celiac, Coeliac, Gluten, Inflammation, Intussusception, Population-based

\section{Background}

Intussusception is a condition in which a segment of intestine invaginates into another section of intestine. Signs and symptoms of intussusception include acute pain, nausea, lethargy, vomiting and sometimes bleeding from the rectum ("red currant jelly") [1]. Although intussusception generally remits spontaneously, in a number of cases either contrast enema or surgery is needed to treat the disorder [2]. The causes of intussusception include infections and vaccination with rotavirus vaccine,

\footnotetext{
* Correspondence: jonasludvigsson@yahoo.com

${ }^{1}$ Clinical Epidemiology Unit, Department of Medicine, Karolinska University Hospital and Karolinska Institutet, Karolinska, Sweden

${ }^{2}$ Department of Pediatrics, Örebro University Hospital, Örebro, Sweden

Full list of author information is available at the end of the article
}

but organic disorders such as malignancy tend to predominate in adults.

Celiac disease $(\mathrm{CD})$ is a chronic inflammatory small intestinal disorder that occurs in about $1-2 \%$ of the general population $[3,4]$. Undiagnosed $C D$ is characterized by small bowel inflammation [5] and will sometimes cause small bowel wall edema [6], intestinal lymph node swelling [7] and dysmotility [7] but also ulcers and strictures [8]. It has therefore been suggested that untreated $\mathrm{CD}$ may be linked to intussusception; a number of casereports and case series substantiate this hypothesishesis [9-14]. In a recent paper from a tertiary institution in the US [14], 3/252 (1.2\%) of children with newly diagnosed CD had a history of intussusception compared with $0.07 \%$ of the child population attending this center.

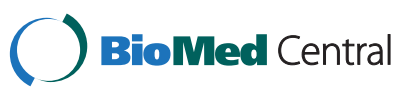


This suggests intussusception may be associated with $\mathrm{CD}$, however, due to small numbers or lack of controls, none of these studies have estimated relative risks or odds ratios (ORs) [9-14].

The main objective of this study was therefore to examine the association between intussusception and later biopsy-verified $\mathrm{CD}$ in a large nationwide populationbased case-control study. In a post-hoc analysis we examined the risk of intussusception in patients who already had a diagnosis of CD.

\section{Methods}

We identified patients with intussusception through the Swedish Patient Register [15] (data on inpatient care, hospital-based outpatient care and day-care surgery). Intussusception data were linked to data on $\mathrm{CD}$ obtained from biopsy reports at Sweden's 28 pathology registers [16]. Linkages were performed using the Swedish personal identity number (PIN) [17].

\section{Intussusception}

Cases with intussusception were identified from the Swedish Patient Register [15] by reference to relevant International Classification of Disease (ICD) codes ICD7: 570.0; ICD-8: 560.0; ICD-9: 560A; and ICD-10: K56.1. In subanalyses we restricted intussusception to cases with surgery or to those who had radiological intervention (code TJG30 or 4780) for intussusception. In a separate analysis we examined the risk of $\mathrm{CD}$ in patients with at least two recorded health care contacts that were due to intussusception.

The Swedish Patient Register started in 1964 and since 1987 the register has nationwide coverage. Day-surgery data were added from 1997 and hospital-based outpatient data since 2001 [15].

\section{Celiac disease}

In 2006-2008 we collected small intestinal biopsy report data from all pathology departments $(n=28)$ in Sweden. The biopsies were performed between 1969 and 2008. IT personnel carried out computerized searches for arrival date of biopsies, PIN [17], morphology and topography (duodenum and jejunum). CD was defined as having a biopsy with villous atrophy (VA, equals Marsh stage 3) [18] according to the Swedish SnoMed classification. We did not require patients to have a positive antibodies against tissue transglutaminase (TTG), endomysium (EMA), or gliadin for a CD diagnosis, but in a random subset of patients with VA and available data on CD serology about $88 \%$ were positive for either of these antibodies at the time of biopsy [16]. An earlier validation of 114 patients with VA found that 108 (95\%) had CD [16]. Approximately $79 \%$ of individuals with CD had gastrointestinal symptoms before biopsy and 35\% had anemia.

\section{Controls}

Each individual undergoing biopsy was matched with up to five controls for age, sex, calendar period and county of residence. Controls were identified from the Total Population Register by the Swedish government agency, Statistics Sweden and had no previous duodenal/jejunal biopsy.

We then excluded individuals whose biopsy may have originated from the ileum, CD individuals lacking a serial number from Statistics Sweden or having no matched controls since all analyses were carried out per stratum. The remaining individuals were identical to those in our study on mortality in CD [19]. Thus, the final sample on which this study is based was 29,096 individuals with CD and 144,522 matched controls.

\section{Statistics}

We used conditional logistic regression to estimate ORs for $\mathrm{CD}$ and earlier intussusception. The conditional approach entails that each individual with $\mathrm{CD}$ is only compared with his or her controls within the same stratum. We also present percentages of CD patients and controls with a previous diagnosis of intussusception.

In pre-defined subanalyses we examined intussusception and CD in relation to sex, age $(0-19,20-39,40-59$ and $\geq 60$ years at age of diagnosis) and calendar period (1989, 1990-1999 and 2000-) at CD diagnosis.

In another pre-defined subanalysis we examined the association between intussusception and $C D$ in children aged $<2$ years (CD: $n=4,589)$. We did so for two reasons. First, in Sweden, CD is often diagnosed in this age group [20], and second, as opposed to adults in which intussusception may be caused by cancers [11], underlying cancers are unusual in childhood when most intussusception is idiopathic. We therefore hypothesized that the association with $\mathrm{CD}$ would be strongest with idiopathic intussusception in infancy and childhood. For consistency, we also examined the risk of intussusception in individuals diagnosed with $C D \geq 2$ years of age (CD: $n=24,507)$. In a post-hoc analysis we excluded all intussusception occurring before the age of 2 years (not equal to the previous analysis in which we examined risk of $\mathrm{CD}$ after the age of 2 years but included intussusceptions occurring before age 2) and calculated OR for future CD.

We also examined the risk of future $\mathrm{CD}$ in patients with at least 2 health care contacts for intussusception (repeated intussusceptions) of which at least one intussusception had to occur before CD diagnosis. Having at least 2 records of intussusception will increase the likelihood that the patient really had intussusception.

Cancer is sometimes the underlying cause of intussusception [11] and CD has been linked to both lymphoproliferative [21] and gastrointestinal cancer [22] (at 
least about the time of $\mathrm{CD}$ diagnosis [23]). To rule out that a positive association between $\mathrm{CD}$ and intussusception would be due to cancer we performed a separate analysis in which we excluded all individuals (CD patients and controls) who ever had a diagnosis of cancer according to the Swedish Cancer Registry (CD: n = 25,869). The Swedish Cancer Registry began in 1958. About $99 \%$ of all cancers are morphologically verified [24] and almost $100 \%$ of all cancers are reported to this register each year [24].

\section{Post-hoc analysis: CD and risk of future intussusception}

In a post-hoc analysis we examined the risk of future intussusception in patients with CD. This analysis was done to explore whether the null relationship that we found between intussusception and later $\mathrm{CD}$ was independent of temporal sequence. In the prospective analysis we used a cohort study design. Individuals with $C D$ were compared with matched reference individuals and followed from biopsy (or matching date) until first event of intussusception, emigration, death or end of followup (Dec 31, 2009), whichever occurred first. We used Cox regression models to calculate hazard ratios (HRs) for the risk of future intussusception in CD. All analyses were internally stratified, i.e. one individual with $\mathrm{CD}$ was only compared with his or her matched reference individuals (within a stratum) before a summary estimate for the whole CD population was calculated. This approach eliminates the influence of matching variables, such as sex, age, county of residence and calendar year at $\mathrm{CD}$ diagnosis. The prospective cohort analysis was based on 29,060 individuals with no earlier record of intussusception and 144,304 matched reference individuals.

SPSS version 20.0 (SPSS Inc, Chicago, IL, USA) was used for all analyses. Statistical significance was defined as $95 \%$ confidence intervals (CIs) for risk estimates (ORs and HRs) not including 1.0.

\section{Ethics}

The study was approved by the regional ethical review board in Stockholm, Sweden. Since none of the participants was contacted and individual information was "anonymized" before the analyses, informed consent was not required by the board.

\section{Results}

The median age at $\mathrm{CD}$ diagnosis was 30 years (range $0-$ 95) (Table 1). Most patients with CD were diagnosed after 1990 since this study was based on computerized biopsy reports and computerized registers were usually introduced in this decade. Data on the sub-cohort of children diagnosed with $C D<2$ years of age are presented in Additional file 1. Slightly more than 6 of 10 study participants (all ages) were women.
Table 1 Characteristics of study participants

\begin{tabular}{|c|c|c|}
\hline & $\begin{array}{l}\text { Matched } \\
\text { controls }\end{array}$ & $\begin{array}{l}\text { Patients with } \\
\text { celiac disease }\end{array}$ \\
\hline Total, n & 144,522 & 29,096 \\
\hline $\begin{array}{l}\text { Age at celiac diagnosis, years } \\
\text { (median, range) }\end{array}$ & * & 30; 0-95 \\
\hline Age 0-19, n (\%) & $58,852(40.7)$ & $11,802(40.6)$ \\
\hline Age $20-39, n(\%)$ & $26,385(18.3)$ & $5,312(18.3)$ \\
\hline Age 40-59, n (\%) & $32,254(22.3)$ & $6,477(22.3)$ \\
\hline Age $\geq 60, n(\%)$ & 27,031 (18.7) & $5,505(18.9)$ \\
\hline Entry year (median, range) & $1998,1969-2008$ & 1998, 1969-2008 \\
\hline Females, n (\%) & $89,544(62.0)$ & $18,005(61.9)$ \\
\hline Males, n (\%) & $54,978(38.0)$ & $11,091(38.1)$ \\
\hline \multicolumn{3}{|l|}{ Calendar year } \\
\hline-1989, n (\%) & $20,378(14.1)$ & $4,105(14.1)$ \\
\hline 1990-99, n (\%) & $59,874(41.4)$ & $12,059(41.4)$ \\
\hline $2000, n(\%)$ & $64,270(44.5)$ & $12,932(44.4)$ \\
\hline \multicolumn{3}{|l|}{ Country of birth } \\
\hline Nordic\# & $136,279(94.3)$ & $28,139(96.7)$ \\
\hline \multicolumn{3}{|c|}{ Data on intussusception } \\
\hline Intussusception n (\%) & $143(0.10)$ & $34(0.12)$ \\
\hline $\begin{array}{l}\text { Age at first intussusception, } \\
\text { years (median, range) }\end{array}$ & $1(0-60)$ & $3(0-68)$ \\
\hline $\begin{array}{l}\text { Intussusception with } \\
\text { surgery/radiology, n (\%) }\end{array}$ & $31(0.02)$ & $8(0.03)$ \\
\hline
\end{tabular}

* Reference individuals were matched for age. The median age at matching was 30 years (range 0-95 years).

\# Sweden, Denmark, Finland, Norway and Iceland.

\section{Intussusception and risk of CD}

Of 29,096 individuals with CD, 34 (0.12\%) had a diagnosis of intussusception vs. 143/144,522 of the controls $(0.10 \%)$. Hence, we found no association between intussusception and later $\mathrm{CD}(\mathrm{OR}=1.17$; 95\% $\mathrm{CI}=0.82-1.67)$. The OR for having a diagnosis of $\mathrm{CD}$ was $1.31(95 \% \mathrm{CI}=0.64-2.68)$ within 1 year after intussusception, $0.56(95 \% \mathrm{CI}=0.17-1.78) 1-<5$ years after intussusception and $1.31(95 \% \mathrm{CI}=0.84-2.05) \geq 5$ years after intussusception.

The risk of future $\mathrm{CD}$ was similar in females $(\mathrm{OR}=0.97 ; 95 \% \mathrm{CI}=0.57-1.66)$ and males $(\mathrm{OR}=1.40$; $95 \% \mathrm{CI}=0.86-2.28$ ) (Table 2 ), and there were no significant differences in ORs according to age at CD diagnosis or calendar year (Table 2). Adjustment for education and country of birth (Nordic vs. Non-Nordic) did not affect our ORs (data not shown).

\section{Subanalyses}

When we restricted our dataset to children $<2$ years of age (at diagnosis of $\mathrm{CD}$ or at date of matching), 6 individuals with $C D$ had a previous intussusception vs. 32 controls. Intussusception was no risk factor for $\mathrm{CD}$ in 
Table 2 Intussusception and risk of later celiac disease

\begin{tabular}{|c|c|c|c|c|c|}
\hline \multirow[t]{2}{*}{ Subgroup } & \multicolumn{2}{|c|}{$\begin{array}{l}\text { Intussusceptions, } \\
\mathrm{N}\end{array}$} & \multirow[t]{2}{*}{ OR; $95 \% \mathrm{Cl}$} & \multirow[t]{2}{*}{$\begin{array}{l}P \text { - } \\
\text { value }\end{array}$} & \multirow[t]{2}{*}{$\begin{array}{l}P \text { for } \\
\text { interaction }\end{array}$} \\
\hline & $\begin{array}{l}\text { Celiac } \\
\text { disease }\end{array}$ & Controls & & & \\
\hline \multicolumn{6}{|l|}{ Sex } \\
\hline Males & 19 & 66 & $1.40 ; 0.86-2.28$ & 0.176 & 0.323 \\
\hline Females & 15 & 77 & $0.97 ; 0.57-1.66$ & 0.922 & \\
\hline \multicolumn{6}{|l|}{ Age F $^{*}$} \\
\hline$<20$ yrs & 20 & 103 & $0.97 ; 0.61-1.54$ & 0.902 & 0.256 \\
\hline $20-39$ yrs & 8 & 23 & $1.67 ; 0.78-3.66$ & 0.186 & \\
\hline $40-59$ yrs & 3 & 6 & $2.34 ; 0.64-8.62$ & 0.201 & \\
\hline $60+y r s$ & 3 & 11 & $1.34 ; 0.39-4.66$ & 0.645 & \\
\hline \multicolumn{6}{|l|}{$\begin{array}{l}\text { Calendar } \\
\text { period* }\end{array}$} \\
\hline-1989 & 7 & 21 & $1.59 ; 0.71-3.56$ & 0.258 & 0.292 \\
\hline 1990-1999 & 14 & 54 & $1.27 ; 0.72-2.22$ & 0.407 & \\
\hline 2000-2008 & 13 & 68 & $0.96 ; 0.54-1.70$ & 0.881 & \\
\hline
\end{tabular}

*At time of celiac disease diagnosis.

this subset of young children (OR $=0.94 ; 95 \% \mathrm{CI}=0.42$ 2.14) (Table 3). Table 3 shows additional data.

Similarly, intussusception was no risk factor for having a diagnosis of $\mathrm{CD}$ after 2 years of age $(\mathrm{OR}=1.24$; $95 \%$ $\mathrm{CI}=0.83-1.86)$. However, we did find a statistically significant association $(\mathrm{OR}=2.11 ; 95 \% \mathrm{CI}=1.26-3.53)$ in a post-hoc analysis that only examined intussusceptions occurring after the age of 2 years and risk of future CD.

Table 3 Subanalyses: Intussusception and risk of later celiac disease

\begin{tabular}{lll}
\hline $\begin{array}{l}\text { Subgroup } \\
\text { Overall }\end{array}$ & $\begin{array}{l}\text { Celiac disease } \\
<2 \text { years } \\
\text { OR; } 95 \% \text { Cl }\end{array}$ & $\begin{array}{l}\text { Intussusception with } \\
\text { radiology\#/surgery } \\
\text { OR; } 95 \% \text { Cl }\end{array}$ \\
\hline Sex & $0.94 ; 0.42-2.14$ & $1.27 ; 0.60-2.69$ \\
Males & $1.55 ; 0.56-4.31$ & $1.07 ; 0.31-3.63$ \\
Females & $0.53 ; 0.13-2.16$ & $1.42 ; 0.55-3.67$ \\
\hline Age $^{*}$ & Not estimated & $0.80 ; 0.24-2.62$ \\
$<20$ yrs & Not estimated & $2.88 ; 0.93-8.91$ \\
$20-39$ yrs & Not estimated & $2.50 ; 0.23-27.57$ \\
$40-59$ yrs & Not estimated & Not estimated\$ \\
$\geq 60$ yrs & & \\
\hline Calendar period ${ }^{*}$ & $1.41 ; 0.44-4.54$ & $2.31 ; 0.48-11.30$ \\
-1989 & $0.59 ; 0.14-2.39$ & $0.94 ; 0.28-3.14$ \\
$1990-1999$ & $1.23 ; 0.15-9.82$ & $1.33 ; 0.39-4.52$ \\
\hline 2000-2008 &
\end{tabular}

*At time of celiac disease diagnosis. \#Radiological intervention for intussusception.

$\S$ No cases of previous intussusception in the $C D$ group vs. four cases in the control group.
Restricting our exposure to intussusception with either radiological intervention or surgery, the OR for future CD was $1.27(95 \% \mathrm{CI}=0.60-2.69)$.

One patient with $\mathrm{CD}$ vs. 13 controls had $\geq 2$ records of intussusception (out of which at least one intussusception occurred before $\mathrm{CD}$ diagnosis and study entry). This outcome corresponded to a non-significant OR of 0.40 for future $\mathrm{CD}(95 \% \mathrm{CI}=0.06-2.99)$. In eleven of the fourteen $(1+13)$ patients with $\geq 2$ records of intussusception, did the two records correspond to the same intussusception (e.g. follow-up visit shortly after first diagnosis). All three patients with $\geq 30$ days between the two intussusceptions (our definition of different episodes), were controls.

Excluding study participants who had a diagnosis of cancer at some stage in life, the OR for future CD in patients with intussusception was $1.10(95 \% \mathrm{CI}=0.76-$ 1.59) $(31 / 25,869 \mathrm{CD}$ patients vs. $140 / 130,041$ controls had an earlier diagnosis of intussusception).

\section{Celiac disease and risk of future intussusception}

Using a prospective cohort approach, a post-hoc analysis found that 12 of 29,060 individuals with CD had a diagnosis of intussusception after CD onset (expected $n=6$ ), corresponding to a hazard ratio and relative risk of 1.95 $(95 \% \mathrm{CI}=1.01-3.77, \mathrm{p}=0.046)$.

\section{Discussion}

To our knowledge this is the first case-control study examining intussusception and risk of future CD. It found no association between intussusception and $\mathrm{CD}$ (overall $\mathrm{OR}=1.17$ ). In a post-hoc analysis intended to confirm the null relationship between prior intussusception and CD before diagnosis we instead found that patients with diagnosed $\mathrm{CD}$ were at an almost twofold increased risk of later intussusception.

Most literature on $\mathrm{CD}$ and intussusception has been limited to case reports or case series [9-13,25]. Germann et al. suggest that intussusception in $\mathrm{CD}$ has a mild clinical course [25]. Intussusception may take place in the duodenum or jejunum but may occur in other parts of the intestine. In our study we were unable to differentiate between intussusceptions in the small intestine and the colon. If intussusception is associated with $C D$, it is most likely associated with small intestinal intussusception and thus the inclusion of colonic intussusception may have diluted a positive relationship. Still, the overall OR for future CD was very close to 1.0, and if there had been a significant association between previous intussusception and CD, this would have appeared in our data. Reilly et al. reported that $1.2 \%$ of their celiac children had experienced a known intussusception [14] but since the authors do not present any statistical comparison with the general population this may or may not 
represent an increase. Our study differs from that of Reilly et al. [14] by different source populations (nationwide approach vs. tertiary institution), and larger number of celiac patients (29,096 vs. 254).

In a recent paper we studied the role of surgery in adult intussusception [11]. In that case series 8/196 (4\%) patients with intussusception had CD [11]. In a paper looking at the risk of intussusception in patients with a diagnosis of CD 14/880 (1.6\%) developed intussusception during follow-up [13]. In both these series, with strong associations between $\mathrm{CD}$ and intussusception, participants were recruited from single tertiary centers, making it is possible that this procedure selected cases with more severe $C D$ and intussusception [11,13], or that these patients were at higher risk of undergoing investigation or contacting health care for a number of disorders. We have previously shown that the relative risk of another disorder in CD (tuberculosis) is twice as high in $\mathrm{CD}$ patients identified through hospital records [26] as in patients identified through biopsy reports [27]. Further, the risk of mortality in CD seems higher in patients with a hospital record of CD [28] than in patients diagnosed through biopsy reports [19]. More than 96\% of pediatricians and gastroenterologists in Sweden perform a biopsy in at least $90 \%$ of patients with suspected $\mathrm{CD}$ before diagnosis [29]. Other strengths of our paper include the high specificity of VA for CD. When two independent reviewers manually scrutinized more than 1500 biopsy reports, very few individuals had other comorbidities than CD $(0.3 \%$ of patients with VA had inflammatory bowel disease and $0.2 \%$ had Helicobacter pylori). The nationwide ascertainment of $\mathrm{CD}$ yielded a large number of $C D$ cases, which contributed to high statistical power. We were therefore able to stratify for age, sex and calendar period at CD diagnosis.

Restricting our analyses to intussusception with radiological intervention and surgery did not affect the OR (1.27). Only after we restricted our analyses to individuals with intussusception after the age of 2 years, did we find a positive association between intussusception and future $\mathrm{CD}$. We urge caution when interpreting these data since they made up a post-hoc finding and could be due to chance. Still, these data may reflect a true association between inflammation from undiagnosed $C D$ in older children and adults and secondary intussusception.

This study has some limitations. We used a case-control design to examine the association between previous intussusception and future CD. This design means that we did not screen individuals with intussusception for serological markers. Still, if any, patients with intussusception would have been more likely to undergo investigation for $\mathrm{CD}$ and this would have driven up the OR for $\mathrm{CD}$. The lack of serological data can therefore not explain our null findings for later CD risk.
We did not have access to radiological data such as computed tomography and thus could not confirm the intussusception diagnosis. However, in several analyses we increased the specificity of intussusception through various restrictions of the dataset and this had only marginal effects on the ORs. Nor did we screen CD patients for intussusception with MRI, CT or ultrasound [7]. Thus, we have no information on the association between $\mathrm{CD}$ and intussusception that did not require health care.

We know of no earlier incidence study of intussusception in Sweden but a study from nearby Germany found an incidence of 60/100,000 person-years in children $<1$ year of age [30]. When we examined control children who were born in 1987 or later (when the Swedish Patient Registry was complete) in our dataset, there were 37 intussusceptions in the first year of life corresponding to an incidence of $83 / 100,000$ (37/44,759 person-years). This incidence suggests that the low OR of our study is unlikely to be due to underreporting of intussusceptions.

Finally, despite the large number of patients, we cannot rule out a weak association between intussusception and later CD since the upper 95\% CI reached 1.67.

Early versions of Rotavirus immunizations have been linked to intussusception [31], and we lacked immunization data. However a recent study from Sweden [32] found no association between childhood immunizations and $\mathrm{CD}$, and rotavirus immunizations have not yet been included in the general childhood immunization program in Sweden. Hence, biased immunization coverage in $\mathrm{CD}$ children is unlikely to explain our results.

\section{Conclusion}

In conclusion, this study found no association between intussusception and $\mathrm{CD}$ before $\mathrm{CD}$ diagnosis (undiagnosed $\mathrm{CD}$ ), but did find a twofold increased risk of intussusception after $\mathrm{CD}$ diagnosis. However, because only $12 / 29,060$ (0.04\%) individuals with CD developed intussusception during follow-up, intussusception is probably a rare complication in $\mathrm{CD}$. This study does not support $\mathrm{CD}$ screening in patients with intussusception.

\section{Additional file}

Additional file 1: Characteristics of study participants with diagnosis of $C D<2$ years of age.

Abbreviations

CD: Celiac disease; Cl: Confidence interval; OR: Odds ratio; VA: Villous atrophy.

Competing interests

The authors declared that they have no competing interest.

\section{Authors' contributions}

ICMJE criteria for authorship read and met: JFL, AN, JAM, OO. Agree with the manuscript's results and conclusions: JFL, AN, JAM, OO. Designed the experiments/the study: JFL and OS. Collected data: JFL. Analyzed the data: 
JFL. Wrote the first draft of the paper: JFL. Contributed to the writing of the paper: AN, JAM, OO. Contributed to the study design and interpretation of the data analyses: JFL, AN, JAM, OO. Approved the final version of the manuscript: JFL, AN, JAM, OO. Responsible for data integrity: JFL. Obtained funding: JFL. Guarantor: JFL had full access to all the data in the study and takes responsibility for the integrity of the data. JFL takes responsibility for the accuracy of the data analyses. All authors read and approved the final manuscript.

\section{Acknowledgement}

Details of ethics approval: This project (2006/633-31/4) was approved by the regional ethical review board in Stockholm on June 14, 2006.

\section{Funding}

JFL was supported by grants from the Swedish Society of Medicine, the Swedish Research Council, the Swedish Celiac Society, and the Fulbright Commission

JAM: The National Institutes of Health -DK057892.

AN was supported by the Swedish Research Council, The Foundation Frimurarna in Stockholm and Stockholm City Council (ALF).

$\mathrm{OO}$ was supported by grants from the Magnus Bergvall Foundation, the Mjölkdroppen Foundation, the Samariten Foundation and Stockholm County.

None of the funders had any influence on this study.

\section{Author details}

Clinical Epidemiology Unit, Department of Medicine, Karolinska University Hospital and Karolinska Institutet, Karolinska, Sweden. ${ }^{2}$ Department of Pediatrics, Örebro University Hospital, Örebro, Sweden. ${ }^{3}$ Division of Gastroenterology and Hepatology, Departments of Medicine and Immunology, Mayo Clinic College of Medicine, Rochester, NY, USA. ${ }^{4}$ Department of Women's and Children's Health, Karolinska Institutet and Department of Pediatric Surgery, Karolinska University Hospital, Karolinska, Sweden. ${ }^{5}$ Sachs' Children's Hospital, Stockholm South General Hospital, Stockholm, Sweden.

Received: 3 October 2012 Accepted: 13 May 2013

Published: 16 May 2013

\section{References}

1. Samad L, Marven S, El Bashir H, Sutcliffe AG, Cameron JC, Lynn R, Taylor B: Prospective surveillance study of the management of intussusception in UK and Irish infants. Br J Surg 2012, 99:411-415.

2. Loukas M, Pellerin M, Kimball Z, de la Garza-Jordan J, Tubbs RS, Jordan R Intussusception: an anatomical perspective with review of the literature. Clin Anat 2011, 24:552-561.

3. Dube C, Rostom A, Sy R, Cranney A, Saloojee N, Garritty C, Sampson M, Zhang $L$, Yazdi F, Mamaladze $V$, et al: The prevalence of celiac disease in average-risk and at-risk Western European populations: a systematic review. Gastroenterology 2005, 128:S57-S67.

4. Walker MM, Murray JA, Ronkainen J, Aro P, Storskrubb T, D'Amato M, Lahr B, Talley NJ, Agreus L: Detection of Celiac Disease and Lymphocytic Enteropathy by Parallel Serology and Histopathology in a PopulationBased Study. Gastroenterology 2010, 139:112-119.

5. Walker MM: Murray. An update in the diagnosis of coeliac disease. Histopathology: JA; 2010.

6. Tomei E, Semelka RC, Braga L, Laghi A, Paolantonio P, Marini M, Passariello R, Di Tola M, Sabbatella L, Picarelli A: Adult celiac disease: what is the role of MRI? J Magn Reson Imaging 2006, 24:625-629.

7. Bartusek D, Valek V, Husty J, Uteseny J: Small bowel ultrasound in patients with celiac disease. Retrospective study. Eur J Radiol 2007, 63:302-306.

8. Schweiger GD, Murray JA: Postbulbar duodenal ulceration and stenosis associated with celiac disease. Abdom Imaging 1998, 23:347-349.

9. Fishman DS, Chumpitazi BP, Ngo PD, Kim HB, Lightdale JR: Small bowe intussusception in celiac disease: revisiting a classic association. J Pediatr Gastroenterol Nutr 2010, 50:237.

10. Mushtaq N, Marven S, Walker J, Puntis JW, Rudolf M, Stringer MD: Small bowel intussusception in celiac disease. J Pediatr Surg 1999, 34:1833-1835.

11. Onkendi EO, Grotz TE, Murray JA, Donohue JH: Adult intussusception in the last 25 years of modern imaging: is surgery still indicated? J Gastrointest Surg 2011, 15:1699-1705.
12. Cohen MD, Lintott DJ: Transient small bowel intussusception in adult coeliac disease. Clin Radiol 1978, 29:529-534.

13. Gonda TA, Khan SU, Cheng J, Lewis SK, Rubin M, Green PH: Association of intussusception and celiac disease in adults. Dig Dis Sci 2010, 55:2899-2903.

14. Reilly NR, Aguilar KM, Green PH: Should intussusception in children prompt screening for celiac disease? J Pediatr Gastroenterol Nutr 2013, 56:56-59.

15. Ludvigsson JF, Andersson E, Ekbom A, Feychting M, Kim JL, Reuterwall C, Heurgren M, Otterblad Olausson P: External review and validation of the Swedish national inpatient register. BMC Public Health 2011, 11:450.

16. Ludvigsson JF, Brandt L, Montgomery SM, Granath F, Ekbom A: Validation study of villous atrophy and small intestinal inflammation in Swedish biopsy registers. BMC Gastroenterol 2009, 9:19.

17. Ludvigsson JF, Otterblad-Olausson P, Pettersson BU, Ekbom A: The Swedish personal identity number: possibilities and pitfalls in healthcare and medical research. Eur J Epidemiol 2009, 24:659-667.

18. Marsh MN: Gluten, major histocompatibility complex, and the small intestine. A molecular and immunobiologic approach to the spectrum of gluten sensitivity ('celiac sprue'). Gastroenterology 1992, 102:330-354.

19. Ludvigsson JF, Montgomery SM, Ekbom A, Brandt L, Granath F: Smallintestinal histopathology and mortality risk in celiac disease. JAMA 2009, 302:1171-1178

20. Ivarsson A, Persson LA, Nystrom L, Ascher H, Cavell B, Danielsson L, Dannaeus A, Lindberg T, Lindquist B, Stenhammar L, Hernell O: Epidemic of coeliac disease in Swedish children [see comments]. Acta Paediatr 2000, 89:165-171.

21. Elfstrom P, Granath F, Ekstrom Smedby K, Montgomery SM, Askling J, Ekbom A, Ludvigsson JF: Risk of Lymphoproliferative Malignancy in Relation to Small Intestinal Histopathology Among Patients With Celiac Disease. J Natl Cancer Inst 2011, 103:436-444.

22. Green PH, Fleischauer AT, Bhagat G, Goyal R, Jabri B, Neugut Al: Risk of malignancy in patients with celiac disease. Am J Med 2003, 115:191-195.

23. Elfstrom P, Granath F, Ye W: Ludvigsson. Low Risk of Gastrointestinal Cancer Among Patients With Celiac Disease, Inflammation, or Latent Celiac Disease. Clin Gastroenterol Hepatol: JF; 2011.

24. Socialstyrelsen: Cancer incidence in Sweden 2005. In Book Cancer incidence in Sweden 2005. City; 2007.

25. Germann R, Kuch M, Prinz K, Ebbing A, Schindera F: Celiac disease: an uncommon cause of recurrent intussusception. J Pediatr Gastroenterol Nutr 1997, 25:415-416.

26. Ludvigsson JF, Wahlstrom J, Grunewald J, Ekbom A, Montgomery SM: Coeliac disease and risk of tuberculosis: a population based cohort study. Thorax 2007, 62:23-28.

27. Ludvigsson JF, Sanders DS, Maeurer M, Jonsson J, Grunewald J, Wahlstrom J: Risk of tuberculosis in a large sample of patients with coeliac diseasea nationwide cohort study. Aliment Pharmacol Ther 2011, 33:689-696.

28. Peters U, Askling J, Gridley G, Ekbom A, Linet M: Causes of death in patients with celiac disease in a population-based Swedish cohort. Arch Intern Med 2003, 163:1566-1572.

29. Ludvigsson JF, Brandt L, Montgomery SM: Symptoms and signs in individuals with serology positive for celiac disease but normal mucosa. BMC Gastroenterol 2009, 9:57.

30. Jenke AC, Klaassen-Mielke R, Zilbauer M, Heininger $U$, Trampisch $H$, Wirth S: Intussusception: incidence and treatment-insights from the nationwide German surveillance. J Pediatr Gastroenterol Nutr 2011, 52:446-451.

31. MMWR Morb Mortal Wkly Replntussusception among recipients of rotavirus vaccine--United States, 1998-1999. 1999, 48:577-581.

32. Myleus A, Stenlund H, Hernell O, Gothefors L, Hammarstrom ML, Persson $L A$, Ivarsson $A$ : Early vaccinations are not risk factors for celiac disease. Pediatrics 2012, 130:e63-e70.

\section{doi:10.1186/1471-230X-13-89}

Cite this article as: Ludvigsson et al: A large nationwide population-based case-control study of the association between intussusception and later celiac disease. BMC Gastroenterology 2013 13:89. 